\title{
Long-Term Effect of Noninvasive Ventilation on Diaphragm in Chronic Respiratory Failure
}

\author{
Ana Hernandez-Voth' \\ Javier Sayas Catalan $\mathbb{D}^{1,2}$ \\ Marta Corral Blanco' \\ Rodrigo Alonso Moralejo ${ }^{3}$ \\ Virginia Perez Gonzalez ${ }^{3}$ \\ Alicia De Pablo Gafas ${ }^{2,3}$ \\ Alba Castaño Menendez' \\ Lourdes Juarros Monteagudo ${ }^{4}$ \\ Victoria Villena Garrido $2,4-6$ \\ 'Department of Pneumology, \\ Mechanical Ventilation Unit, 12 de \\ Octubre University Hospital, Madrid, \\ Spain; ${ }^{2}$ Department of Medicine, \\ Faculty of Medicine, Universidad \\ Complutense de Madrid, Madrid, Spain; \\ ${ }^{3}$ Department of Pneumology, Lung \\ Transplantation Unit, 12 de Octubre \\ University Hospital, Madrid, Spain; \\ ${ }^{4}$ Department of Rehabilitation, Lung \\ Transplantation Unit, 12 de Octubre \\ University Hospital, Madrid, Spain; \\ ${ }^{5}$ Department of Pneumology, 12 de \\ Octubre University Hospital, Madrid, \\ Spain; ${ }^{6}$ Department of Research. \\ Center for Biomedical Research on \\ Respiratory Diseases (CIBERES), \\ Madrid, Spain
}

Correspondence: Ana Hernandez-Voth Department of Pneumology, Mechanical Ventilation Unit, 12 de Octubre University Hospital, Madrid, Spain Tel +34681060165

Email anahvoth@gmail.com
Purpose: Home non-invasive ventilation (NIV) is recommended in patients with COPD and hypercapnic chronic respiratory failure (HCRF). The mechanism by it can improve alveolar ventilation during spontaneous breathing is not yet completely explained. Our aim is to evaluate the impact of on diaphragm muscle function in a series of patients with HCRF.

Patients and Methods: Observational, longitudinal, prospective study of a series of patients with very severe chronic obstruction to airflow treated with home high imntensity NIV (HINIV). Patients underwent a baseline and after 12 months assessment including adherence to treatment, quality of life, respiratory function tests and diaphragmatic ultrasound. SPSS v.26 software was used for statistical analysis.

Results: We studied 30 patients, $63 \%$ male, the mean age was $60.8( \pm 6.4)$ years old. Patients had a severe obstructive ventilatory pattern [FEV1 $21.8( \pm 6.1) \%$ ] and hypercapnia [pCO2 $56.4( \pm 7.2)$ $\mathrm{mmHg}$. After 12 months of HINIV, we observed significant increases in FVC of $9.2 \%(p=0.002)$, FEV1 of 3.5\% ( $=0.04)$, MIP of 9.4\% $(p=0.006)$, and 6-minute-walking test (6MWT) of $31.9 \mathrm{~m}(\mathrm{p}=0.001)$, as well as decreases in $\mathrm{paCO} 2$ of $12.5 \mathrm{mmHg}(\mathrm{p}=0.001), \mathrm{HCO} 3$ of 4.7 $\mathrm{mmol} / \mathrm{L}(\mathrm{p}=0.001)$ and BODE index from 7 to 6 . Diaphragmatic ultrasound demonstrated an increase in the thickening fraction of $14 \%(p=0.002)$. Respiratory symptoms $(p=0.04)$, physical function $(\mathrm{p}=0.03)$, and sleep $(\mathrm{p}=0.04)$ also improved.

Conclusion: In patients with HCRF due to very severe chronic obstruction to airflow, long-term HINIV can improve respiratory performance by improving the function of the diaphragmatic musculature. Larger multicenter clinical trials are needed to confirm the results suggested in this study.

Keywords: COPD, diaphragmatic ultrasound

\section{Introduction}

In recent years, several studies have been published to determine whether at-home noninvasive mechanical ventilation (NIV) has any impact on lung function, exacerbations, quality of life, or survival of patients with hypercapnic chronic respiratory failure (HCRF), with contradictory results. ${ }^{1-4}$ But later trials that used a form of NIV with significantly higher inspiratory positive airway pressure (IPAP) demonstrated improved gas exchange, lung function, ventilatory patterns, cachexia, and even quality of life. ${ }^{5-10}$ Since the application of the high-intensity NIV (HINIV) strategy, substantial benefits have been reported in patients with chronic obstructive pulmonary disease (COPD) and hypercapnia, including greater survival, ${ }^{11-14}$ and quality of life according with the Severe Respiratory Insufficiency Questionnaire (SRI). ${ }^{15}$

The multiple benefits of NIV have been decisive in considering the indication of home NIV in patients with HCRF, ${ }^{16}$ and current international guidelines support it. ${ }^{17}$ There is even a consensus document on its monitoring. ${ }^{18}$ 
But the mechanism by which NIV can improve alveolar ventilation even during spontaneous breathing is not yet completely clear. Hill et al, in 1993, were the first to hypothesize that it is probably due to a multifactorial process including three mechanisms: the "resensitization" of the respiratory centers with diminished hypercapnia, the improvement of lung mechanics through increased lung compliance, and the strengthening of the respiratory musculature thanks to an improvement of nighttime rest provided by respiratory support that unburdens the respiratory musculature. ${ }^{19}$ Of these theories, the effect of NIV on the respiratory musculature is the less clear possible mechanism.

Among the techniques for the functional evaluation of the diaphragm, the gold standard is transdiaphragmatic pressure via the esophagus, but it is an invasive method that is not available in all centers. Functional respiratory tests such as those of maximal inspiratory pressure (MIP) and forced vital capacity (FVC) are simple and noninvasive but not very sensitive. In recent years, the development of diaphragmatic ultrasound has led to a revolution in evaluating diaphragm morphology and function in real time, facilitating the monitoring of the patient without exposure to radiation, and it is affordable and ubiquitous $^{20}$ since it is a noninvasive and reproducible technique that can be performed at the bedside and has no contraindications. ${ }^{21}$ Its use is well established for evaluating the probability of a successful or failed mechanical ventilation (MV) weaning in critical patients, ${ }^{22}$ and its application in daily clinical practice in noncritical patients is increasingly expanding to the evaluation of the effect of rehabilitation on the diaphragm in patients with $\mathrm{COPD}^{23}$ and to the prediction of NIV success in patients with exacerbations. $^{24}$

The objective of this study was to evaluate the impact of home NIV on pulmonary function, emphasizing its effect in respiratory muscle function by performing lung function test and diaphragmatic ultrasound in a series of patients with HCRF due to chronic obstructive airflow.

\section{Patients and Methods}

This was an observational, longitudinal, prospective study of a series of patients in follow-up at a lung transplant unit, who had been diagnosed with very severe chronic obstruction to airflow due to COPD, primary ciliary dyskinesia and bronchiectasis, treated with home NIV due to diurnal hypercapnia, observed in at least two arterial blood gas test results, despite optimized treatment. In all patients, significant comorbidities were studied that could interfere as confounding factors in the results of this study, using tests that ruled out heart disease (echocardiogram, normal electrocardiogram and catheterization), obesity (normal BMI), or sleep apnea-hypopnea syndrome (Epworth Sleep Scale not suggestive of this syndrome).

Inclusion criteria was: (1) diagnosis of severe or very severe chronic obstruction to airflow, (2) daytime hypercapnia in at least two sample of blood gas test, (3) optimized treatment, including combination inhalers according with the phenotype and a 12-week in-hospital rehabilitation program before the inclusion in this study. Exclusion criteria was (1) rejection or intolerance to NIV treatment, (2) receiving a lung transplantation during the study, not completing a period of at least 8 months of NIV treatment.

Ventilators configured in assisted pressure-controlled support mode were used, connected to oxygen, with a single-limb passive circuit and a calibrated intentional leak placed in a facial mask.

The adaptation to NIV began as outpatient care in the NIV adaptation room of the mechanical ventilation unit, for approximately 120 minutes in a reclining chair while monitoring the pulse oximetric and flow/volume curves of the ventilator. After a month of adequate tolerance and home compliance, in-hospital readjustment was performed for 48-72 hours with pulse oximetry monitoring, transcutaneous capnography, and flow/volume curves by polygraphy with an external pneumotachograph and multiple signal analysis with Power Lab $^{\circledR}$ (ADInstruments, UK) until the patient had adapted to high-intensity NIV.

All patients underwent a baseline assessment before adaptation to NIV and after 12 months. The following data was obtained:

\section{Clinical Data}

Age, sex, height, weight, BMI, and SRI quality of life questionnaire. $^{15}$

\section{Respiratory Functional Tests}

Spirometry: FVC, forced expiratory volume in the first second $\left(\mathrm{FEV}_{1}\right), \mathrm{FEV}_{1} / \mathrm{FVC}$ (JaegerMasterScope, CareFusion, Hoechberg, Germany). Plethysmography: total lung capacity (TLC), residual volume (RV), functional residual capacity (FRC), RV/TLC (JaegerMasterScope, CareFusion, Hoechberg, Germany). Maximum pressures: maximal inspiratory pressure (MIP) (MicroRPM, CareFusion, Hoechberg, Germany). Physical condition: 6-minute walking test (6MWT) (Pulsox 300i, 
Konica Minolta, Tokyo, Japan). Arterial blood gases: $\mathrm{pH}$, $\mathrm{paCO}_{2}, \quad \mathrm{paO}_{2}$, and $\mathrm{HCO}_{3}$ (Gem Premier 4000, Instrumentation Laboratory, Bedford, MA, USA),

\section{Imaging Tests}

Diaphragm ultrasound: thickness at FRC and TLC, and thickening fraction (thickness at TLC - thickness at FRC/ thickness at FRC $\times 100$ ) (Ultrasound Digital Color Doppler X3, Sonoscape Medical Corp, Guangdong, China). Ultrasounds were all performed by the same person, and with the same equipment.

\section{Respirator Data}

Software analysis of the ResScan ${ }^{\circledR}$ respirator (ResMed, Australia), VIVO $50^{\circledR}$ (Breas Medical, Sweden), and Orchestrator $^{\circledR}$ (Philips, USA). These included hours of use, IPAP, expired positive airway pressure (EPAP), and asynchronies.

For the statistical analysis, SPSS v.26 software $\left(\mathrm{IBM}^{\circledR}\right.$ SPSS Inc., Chicago, IL, USA) was used. The values are expressed as mean with standard deviation (SD) or median with ranges, depending on whether the distribution of the data was normal or not. To compare the changes in the measured variables of the patients during treatment, tests were used for the analysis of related samples: Wilcoxon signed-rank test (nonnormal distribution) and Student's $t$-test (normal). A $p<0.05$ was established as statistically significant.

This study followed the principles of the Declaration of Helsinki, the International Council for Harmonization of Technical Requirements for Pharmaceuticals for Human Use guidelines of Good Clinical Practice, and all relevant regulations. All lungs were donated voluntarily with written informed consent and conducted in accordance with the Declaration of Istanbul. Organ donation is coordinated and supervised according with national regulatory guidelines by the Organización Nacional de Transplantes, in Spain.

All patients were detailly informed and signed an informed consent. The protocol, informed consent forms, patient information sheet, and applicable documents were approved in writing by the hospital's Medical Research Ethics Committee (No CEIm: 21/136).

\section{Results}

Of the 44 patients eligible for the study, two were excluded due to intolerance and rejection of NIV, and 12 patients received a transplant during the follow-up period so they could not complete the study protocol. Finally, 30 patients with very severe chronic obstruction to airflow and HCRF were included from the lung transplant unit (Figure 1).

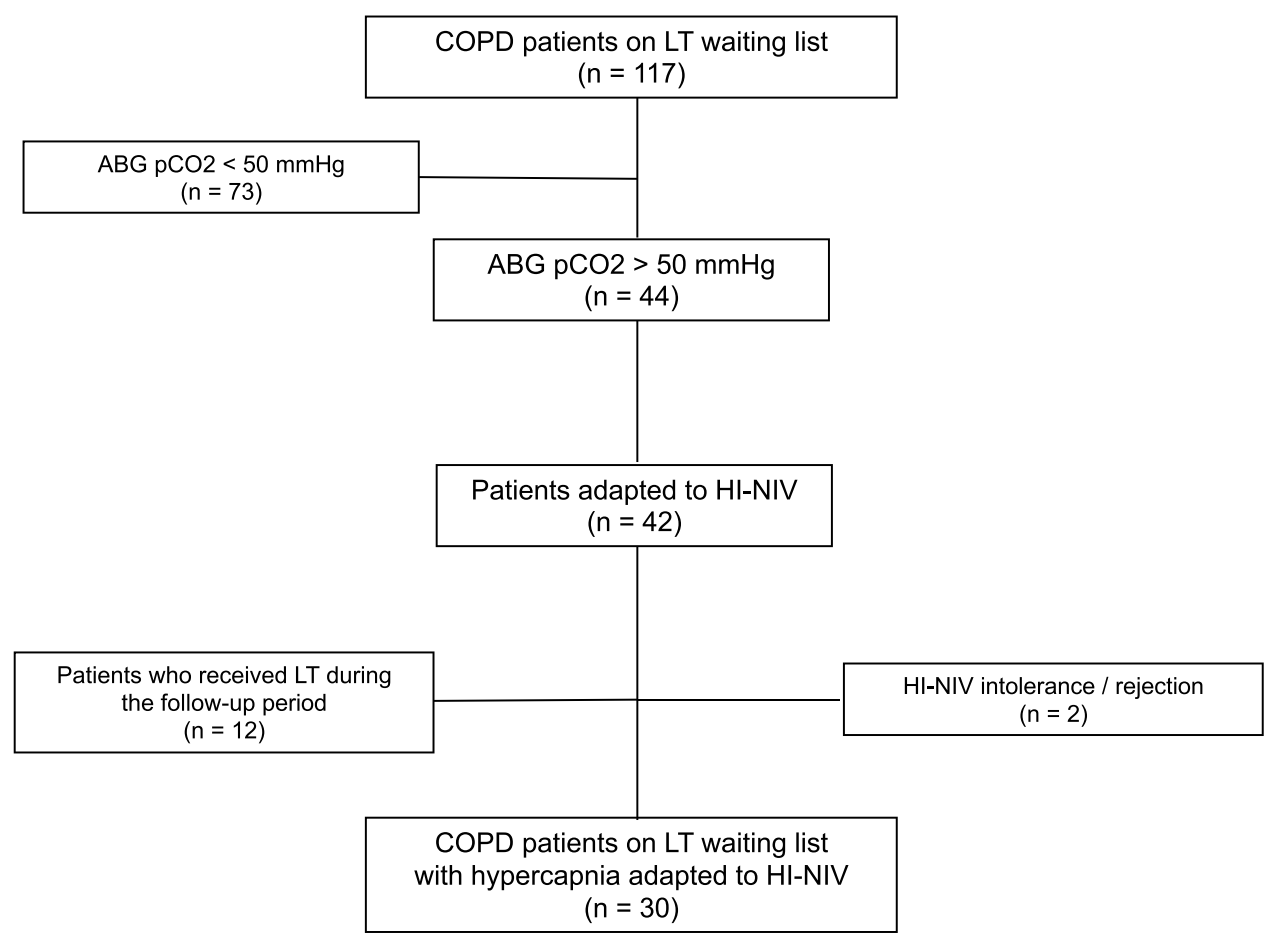

Figure I Diagram of the patient selection process.

Abbreviations: LT, lung transplantation; ABG, arterial blood gas; HI-NIV, high intensity non-invasive mechanical ventilation. 
Most patients had COPD (83\%). The general characteristics of the population are described in Table 1.

The respirators used were the Lumis ${ }^{\circledR} 17$ (57\%), Stellar $^{\circledR} 5(17 \%)$, Astral ${ }^{\circledR} 3(10 \%)$, VPAP S9 ${ }^{\circledR} 2(7 \%)$, Trilogy $150^{\circledR} 2(7 \%)$, and VIVO $50^{\circledR} 1(2 \%)$. The median IPAP was $24 \mathrm{cmH}_{2} \mathrm{O}$ (range 16-36), and EPAP was 10 $\mathrm{cmH}_{2} \mathrm{O}$ (range 5-12). The software for each respirator was evaluated to obtain detailed data for each patient. Compliance was $8.6 \pm 3.03$ hours/day. The most common patient-ventilator asynchronies were ineffective effort in three patients, delayed triggering in one patient, and flow demand in one patient.

After an average of $12.3 \pm 3.5$ months of HINIV use, we observed statistically significant increases in FVC of $9.2 \%$ $(\mathrm{p}=0.002), \mathrm{FEV}_{1}$ of $3.5 \%(\mathrm{p}=0.04)$, MIP of $9.4 \%(\mathrm{p}=0.006)$, and the 6MWT of 31.9 meters $(\mathrm{p}=0.03)$ and decreases in $\mathrm{paCO}_{2}$ of $12.5 \mathrm{mmHg}(\mathrm{p}=0.001)$ and $\mathrm{HCO}_{3}$ of $4.7 \mathrm{mmol} / \mathrm{L}$ $(\mathrm{p}=0.001)$ (Table 2). The increase in the values of $\mathrm{FEV}_{1}$ and the distance traveled during the $6 \mathrm{MWT}$ yielded a reduction in the BODE index from 6.7 to 6 points $(\mathrm{p}=0.001)$ (Table 2).

After the follow-up period, we did not observe effects attributable to NIV on pulmonary hyperinflation, which was diagnosed in all patients at the time of inclusion in the study, in terms of either RV/TLC or FRC (Table 2).

Table I General Characteristics of the Studied Population

\begin{tabular}{|c|c|}
\hline Sex & \\
\hline Male, n (\%) & $19(63 \%)$ \\
\hline Female, n (\%) & II (37\%) \\
\hline Pulmonary disease & \\
\hline COPD, n (\%) & $25(83 \%)$ \\
\hline Primary ciliary dyskinesia, n (\%) & $2(7 \%)$ \\
\hline Bronchiectasis, n (\%) & $3(10 \%)$ \\
\hline Age, mean (SD), yr & $60.8( \pm 6.4)$ \\
\hline BMI, mean (SD), kg/m2 & $24( \pm 3.7)$ \\
\hline FVC, mean (SD), \% & $54.8( \pm 14.1)$ \\
\hline FEVI, mean (SD), \% & $21.8( \pm 6.1)$ \\
\hline FEVI/FVC, mean (SD) & $34( \pm 12.5)$ \\
\hline TLC, mean (SD), \% & $145.13( \pm 65.2)$ \\
\hline $\mathrm{RV}$, mean (SD), \% & $266.9( \pm 76.4)$ \\
\hline 6MWT, mean (SD), meters & $261( \pm 89.6)$ \\
\hline
\end{tabular}

Abbreviations: BMI, body mass index; FEVI, forced expiratory volume in I second; FVC, forced vital capacity; TLC, total lung capacity; RV, residual volume; $6 \mathrm{MWT}$, six minutes walking test.
Diaphragmatic ultrasound was performed at the time of adaptation to NIV and at $12.3 \pm 3.5$ months. We observed a median increase in diaphragm thickness of $0.4 \mathrm{~mm}$ at FRC and $0.3 \mathrm{~mm}$ at TLC and a statistically significant increase in the thickening fraction of $14 \%(\mathrm{p}=0.002)$ (Table 2).

Quality of life increased after $12.3 \pm 3.5$ months of follow-up in all the parameters that make up the IRS questionnaire. ${ }^{13}$ The statistically significant differences were related to respiratory symptoms $(\mathrm{p}=0.04)$, physical function $(\mathrm{p}=0.03)$, and accompanying symptoms and sleep $(\mathrm{p}=0.04)$. The total score of the questionnaire also showed a statistically significant improvement in overall quality of life associated with home NIV ( $\mathrm{p}=0.03$ ) (Table 3 ).

\section{Discussion}

Our study suggests that in patients with very severe chronic obstruction to airflow, hypercapnia and pulmonary hyperinflation, HINIV decreases hypercapnia, increases quality of life, and improves the outcomes of respiratory function tests in a statistically significant way, which we interpret as an overall improvement in lung function. This improvement is probably attributable to the strengthening of the respiratory musculature, as suggested by the results of increased FVC, MIP, and thickening fraction of the diaphragm (Figure 2).

The theory regarding NIV strengthening respiratory muscles is not entirely clear. Nickol et al failed to demonstrate an increase in respiratory muscle strength with lung function tests nor with esophageal measures of transdiaphragmatic pressure. These authors attributed improved alveolar ventilation to compensation of high intrinsic endexpiratory pressure due to gas trapping, and to the bulbar respiratory center's increased sensitivity to the hypercapnic response. ${ }^{25,26}$ However, they evaluated patients 3 months after the start of home NIV, and in only two of 10 patients was the use greater than 4 hours/day. In our series, the respiratory musculature was evaluated at 12 months after adaptation to home NIV, and patients had a mean compliance greater than 8 hours a day. It is possible that the strengthening of the respiratory muscles observed in this study is related to the longer follow-up and greater daily hours of NIV. Windisch ${ }^{7}$ also described an increase in MIP with HINIV in 14 patients with hypercapnic failure due to COPD, but this increase was not statistically significant, again probably due to a minor length of treatment in comparison with our series (6 versus 12 months). 
Table 2 Mean Values of the Tests Performed Before and After 12 Months of Home NIV

\begin{tabular}{|c|c|c|c|}
\hline Visit & Baseline & Follow-Up & $\mathbf{p}$ \\
\hline BMI, mean (SD) & $24(3.7)$ & $23.5(3.1)$ & 0.185 \\
\hline BODE Index, mean (SD) & $6.7(0.9)$ & $6(1.1)$ & 0.001 \\
\hline FVC, mean (SD), mL & |89|.3 (632.9) & $2165.8(665.7)$ & 0.001 \\
\hline FVC, mean (SD), \% & $54.8(14.1)$ & $64(20.2)$ & 0.002 \\
\hline FEVI, mean (SD), mL & $610.3(199.2)$ & $664.4(230.9)$ & 0.04 \\
\hline FEVI, mean (SD), \% & $21.9(6.1)$ & $25.4(8.6)$ & 0.001 \\
\hline FEVI/FVC, mean (SD) & $34(12.5)$ & $33.2(13.2)$ & 0.2 \\
\hline TLC, mean (SD), mL & $7825.9(2480.7)$ & $7212.6(2623.6)$ & 0.82 \\
\hline TLC, mean (SD), \% & |45.| (65.3) & $134.7(35.3)$ & 0.57 \\
\hline $\mathrm{RV}$, mean (SD), mL & $6085.5(1734)$ & $5691.5(2034.9)$ & 0.98 \\
\hline $\mathrm{RV}$, mean (SD), \% & $266.9(76.4)$ & $266.7(97.1)$ & 0.39 \\
\hline RV/TLC, mean (SD) & $194.2(24.3)$ & $194.4(22.5)$ & 0.98 \\
\hline RFC, mean (SD), \% & $217(48.8)$ & $220(58)$ & 0.76 \\
\hline MIP, mean (SD), \% & $48.8(15.3)$ & $58.2(17.5)$ & 0.006 \\
\hline 6MWT, mean (SD), meters & $261(89.6)$ & $292.9(101.8)$ & 0.03 \\
\hline $\mathrm{pH}$, mean $(\mathrm{SD})$ & $7.39(0.04)$ & $7.40(0.02)$ & 0.43 \\
\hline $\mathrm{paCO} 2$, mean (SD), mmHg & $56.4(7.2)$ & $43.9(5.7)$ & 0.001 \\
\hline $\mathrm{paO} 2$, mean (SD), $\mathrm{mmHg}$ & $70.7(17.3)$ & $70.6(16.6)$ & 0.87 \\
\hline $\mathrm{HCO}$, mean (SD), mmol/L & $34.6(4)$ & $29.9(2.9)$ & 0.001 \\
\hline Thickness at FRC, median (range), $\mathrm{mm}$ & $2(1.3-6)$ & $2.4(0.9-3.4)$ & 0.5 \\
\hline Thickness at TLC, median (range), mm & $2.6(1.5-8)$ & $2.9(1.5-8.4)$ & 0.26 \\
\hline Thickening Fraction, median (range), \% & $34(10-78)$ & $48(20-96)$ & 0.002 \\
\hline
\end{tabular}

Abbreviations: NIV, non-invasive ventilation; BMI, body mass index; FVC, forced vital capacity; FEVI, forced expiratory volume in I second; TLC, total lung capacity; RV, residual volume; MIP, maximum inspiratory pressure; $6 \mathrm{MWT}$, six minutes walking test; FRC, functional respiratory capacity.

Table 3 Quality of Life Measures in SRI Questionnaire Before and After 12 Months of Home NIV

\begin{tabular}{|l|c|c|c|}
\hline Visit & Baseline & Follow-Up & p \\
\hline Respiratory complaints, mean (SD) & $27.1( \pm 12.7)$ & $34.4( \pm 16.7)$ & 0.04 \\
Physical functioning, mean (SD) & $48.1( \pm 21)$ & $58.6( \pm 20.9)$ & 0.03 \\
Attendant symptoms and sleep, mean (SD) & $49( \pm 15.9)$ & $62( \pm 14.1)$ & 0.04 \\
Social relationships, mean (SD) & $77.1( \pm 13.9)$ & $78.8( \pm 13)$ & 0.6 \\
Anxiety, mean (SD) & $59.6( \pm 19)$ & $62.1( \pm 20.2)$ & 0.4 \\
Psychological well-being, mean (SD) & $58.6( \pm 18.9)$ & $61.8( \pm 17.4)$ & 0.3 \\
Social functioning, mean (SD) & $41.6( \pm 19.9)$ & $47( \pm 21.1)$ & 0.2 \\
\hline Global SRI index, mean (SD) & $51.3( \pm 13.4)$ & $58.2( \pm 13.2)$ & 0.03 \\
\hline
\end{tabular}

Abbreviations: SRI, severe respiratory insufficiency; NIV, noninvasive mechanical ventilation.

Diaphragmatic ultrasound was incorporated as a method of assessment of the diaphragm. We have observed that, far from achieving an atrophic effect on muscle, high-intensity NIV with a compliance of more than 8 hours a day over more than 12 months, may increase the capacity of contraction of the diaphragm muscle, as suggested with the demonstrated increase in its thickening fraction (Figure 3).

Our results coincide with those recently described by Cammarota et al, who described an increase in the expiratory diaphragm thickness in patients with COPD who adapted well to NIV. ${ }^{27}$

There was an overall improvement in the quality of life of our patients after 12 months of home NIV, which was statistically significant, but particularly in the areas of respiratory, physical, and sleep symptoms. Patients described improvement in dyspnea, greater physical exercise capacity, and improved sleep quality. These results align with those of other studies of high-intensity NIV strategies. Windisch et $\mathrm{al}^{8}$ described a remarkable 


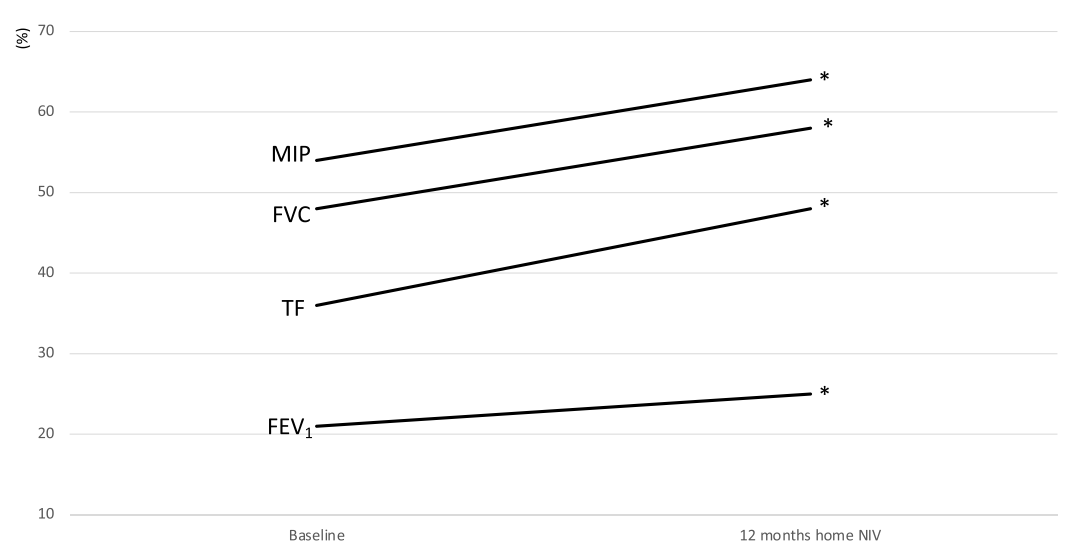

Figure 2 Evolution of lung function tests and diaphragmatic ultrasound before and after home NIV. ${ }^{*} \mathrm{p}<0.05$.

Abbreviations: MIP, maximum inspiratory pressure; FVC, forced vital capacity; TF, diaphragmatic ultrasound thickening fraction; FEVI, forced expiratory volume in the first second.
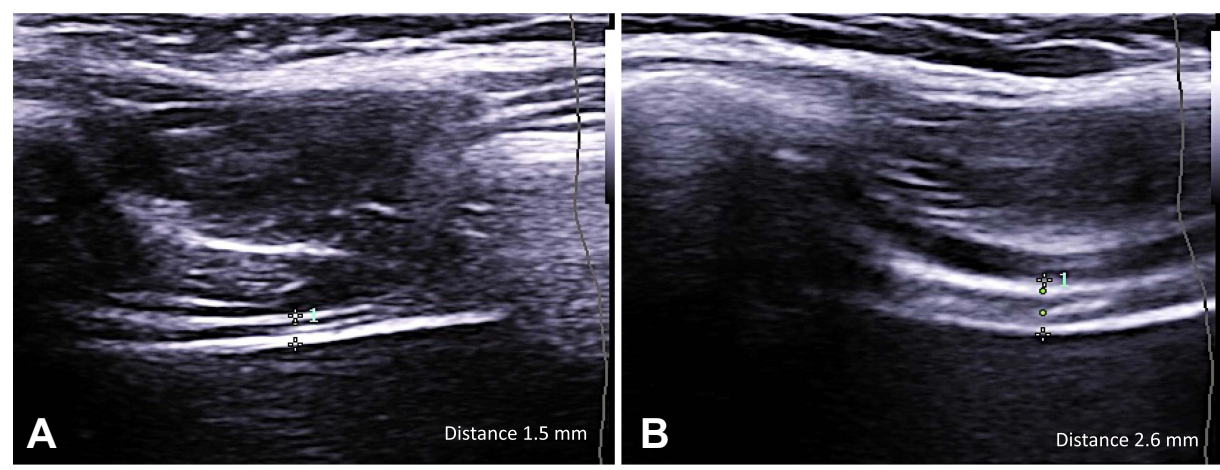

Figure 3 Ultrasound evaluation of diaphragmatic thickness.

Notes: (A) diaphragmatic thickness at residual functional capacity. (B) diaphragmatic thickness at total lung capacity.

improvement in quality of life after only 2 months of HINIV in CODP patients, as did later Dreher et $\mathrm{al}^{14}$ demonstrating no deterioration in sleep quality nor affectation of sleep phases when comparing with NIV strategies with lower pressures.

In recent years there has been growing evidence that in patients with COPD, malnutrition, low body weight, and weight loss are independent and negative risk factors for survival. ${ }^{9}$ Malnutrition, defined by a BMI of $20 \mathrm{~kg} / \mathrm{m} 2$, is frequent in these patients and related to respiratory impairment, particularly hyperinflation and hypercapnia. However, in our patients malnutrition was not detected at the beginning of the study, and after 12 months of follow-up, we observed a slight and no significant decrease in BMI (mean BMI 24 versus 23.5) (Table 2). After 12 months of HINIV, nutritional status of the patients remained stable. In this matter, our results differ with the studies of Budweiser et al, ${ }^{9,10}$ who described an important weight gain in COPD patients after receiving NIV, but those patients were initially malnourished unlike the patients of our study.

As important limitations of this study, we recognize that this was a selected population of patients whose involvement was basically respiratory, since being candidates for lung transplantation, they had no comorbidities that are frequent in patients with severe chronic obstruction to airflow due to COPD, such as coronary artery disease systolic dysfunction, although beneficial hemodynamic effects of NIV have been documented in cardiac patients thanks to decreased afterload, ${ }^{28}$ reduced pulmonary vascular resistance secondary to improved gas exchange, reduced natriuretic peptides with the consequent decrease in systemic blood pressure, ${ }^{29}$ and decreased levels of $\mathrm{N}$-terminal pro-brain natriuretic peptide. ${ }^{30}$ On the other hand, 
the requirement that these patients had mainly chronic obstruction to airflow and no other comorbidities as possible confounding factors made it possible to analyze from a very physiological point of view the effects of home NIV in this population. Another limitation was the absence of a control group without NIV. Such a group was difficult to justify on an ethical level, given that all patients in this study adapted to home NIV with the medical indication being daytime hypercapnia demonstrated by arterial blood gas analysis. Duiverman et $\mathrm{al}^{13}$ did study the benefits of NIV when added to a full program of rehabilitation after 2 years and compared them with rehabilitation alone. These authors describe improvements in quality of life, dyspnea, gas exchange, exercise tolerance and lung function decline in the group of patients receiving rehabilitation plus NIV.

Long-term high-intensity home NIV can improve overall lung function in patients with very severe chronic obstruction to airflow and global CRF, probably by improving the function of the diaphragmatic musculature, leading to a significant improvement in the patient's quality of life. Larger multicenter clinical trials are needed to confirm the results suggested in this study.

\section{Disclosure}

Dr Javier Sayas Catalan reports grants from Menarini, personal fees from Resmed, personal fees from Philips Respironics, outside the submitted work. The authors report no cother conflicts of interest in this work.

\section{References}

1. Casanova C, Celli BR, Tost L, et al. Long-term controlled trial of nocturnal nasal positive pressure ventilation in patients with severe COPD. Chest. 2000;118(6):1582-1590. doi:10.1378/chest.118.6.1582

2. Clini E, Sturani C, Rossi A, et al. The Italian multicentre study on noninvasive ventilation in chronic obstructive pulmonary disease patients. Eur Respir J. 2002;20(3):529-538. doi:10.1183/ 09031936.02.02162001

3. Wijkstra PJ, Lacasse Y, Guyatt GH, et al. A meta-analysis of nocturnal noninvasive positive pressure ventilation in patients with stable COPD. Chest. 2003;124(1):337-343. doi:10.1378/chest.124.1.337

4. Kolodziej MA, Jensen L, Rowe B, Sin D. Systematic review of noninvasive positive pressure ventilation in severe stable COPD. Eur Respir J. 2007;30(2):293-306. doi:10.1183/09031936.00145106

5. Windisch W, Haenel M, Storre JH, Dreher M. High-intensity non-invasive positive pressure ventilation for stable hypercapnic COPD. Int J Med Sci. 2009;6(2):72-76. doi:10.7150/ijms.6.72

6. Windisch W, Vogel M, Sorichter S, et al. Normocapnia during nIPPV in chronic hypercapnic COPD reduces subsequent spontaneous PaCO2. Respir Med. 2002;96(8):572-579. doi:10.1053/ rmed.2002.1326

7. Windisch W, Dreher M, Storre JH, Sorichter S. Nocturnal non-invasive positive pressure ventilation: physiological effects on spontaneous breathing. Respir Physiol Neurobiol. 2006;150 (2-3):251-260. doi:10.1016/j.resp.2005.05.017
8. Windisch W, Criee CP. [Quality of life in patients with home mechanical ventilation]. Pneumologie. 2006;60(9):539-546. German. doi:10.1055/s-2006-932152

9. Budweiser S, Heinemann F, Meyer K, Wild PJ, Pfeifer M. Weight gain in cachectic COPD patients receiving noninvasive positive-pressure ventilation. Respir Care. 2006;51(2):126-132.

10. Budweiser S, Jorres RA, Riedl T, et al. Predictors of survival in COPD patients with chronic hypercapnic respiratory failure receiving noninvasive home ventilation. Chest. 2007;131(6):1650-1658. doi: $10.1378 /$ chest.06-2124

11. Duiverman ML, Wempe JB, Bladder G, et al. Two-year home-based nocturnal noninvasive ventilation added to rehabilitation in chronic obstructive pulmonary disease patients: a randomized controlled trial. Respir Res. 2011;12:112. doi:10.1186/1465-9921-12-112

12. Kohnlein T, Windisch W, Kohler D, et al. Non-invasive positive pressure ventilation for the treatment of severe stable chronic obstructive pulmonary disease: a prospective, multicentre, randomised, controlled clinical trial. Lancet Respir Med. 2014;2 (9):698-705. doi:10.1016/S2213-2600(14)70153-5

13. Duiverman ML, Wempe JB, Bladder G, et al. Nocturnal non-invasive ventilation in addition to rehabilitation in hypercapnic patients with COPD. Thorax. 2008;63(12):1052-1057. doi:10.1136/ thx.2008.099044

14. Dreher M, Ekkernkamp E, Walterspacher S, et al. Noninvasive ventilation in COPD: impact of inspiratory pressure levels on sleep quality. Chest. 2011;140(4):939-945. doi:10.1378/chest.11-0253

15. Windisch W, Freidel K, Schucher B, et al. The Severe Respiratory Insufficiency (SRI) Questionnaire: a specific measure of health-related quality of life in patients receiving home mechanical ventilation. $J$ Clin Epidemiol. 2003;56(8):752-759. doi:10.1016/ S0895-4356(03)00088-X

16. White DP, Dreher M, Hart N, et al. The role of noninvasive ventilation in the management and mitigation of exacerbations and hospital admissions/ readmissions for patients with moderate to severe COPD (multimedia activity). Chest. 2015;147:1704-1705. doi:10.1378/chest.15-0394

17. Ergan B, Oczkowski S, Rochwerg B, et al. European Respiratory Society guidelines on long-term home non-invasive ventilation for management of COPD. Eur Respir J. 2019;54(3):1901003. doi:10.1183/13993003.01003-2019

18. Ambrosino N, Vitacca M, Dreher M, et al. Tele-monitoring of ventilator-dependent patients: a European Respiratory Society Statement. Eur Respir J. 2016;48(3):648-663. doi:10.1183/ 13993003.01721-2015

19. Hill NS. Noninvasive ventilation. Does it work, for whom, and how? Am Rev Respir Dis. 1993;147(4):1050-1055. doi:10.1164/ajrccm/ 147.4.1050

20. Sayas Catalan J, Hernandez-Voth A, Villena Garrido MV. Diaphragmatic ultrasound: an innovative tool has become routine. Arch Bronconeumol. 2020;56(4):201-203. doi:10.1016/j.arbr.2019.06.017

21. Matamis D, Soilemezi E, Tsagourias M, et al. Sonographic evaluation of the diaphragm in critically ill patients. Technique and clinical applications. Intensive Care Med. 2013;39(5):801-810. doi:10.1007/ s00134-013-2823-1

22. Llamas-Alvarez AM, Tenza-Lozano EM, Latour-Perez J. Diaphragm and lung ultrasound to predict weaning outcome: systematic review and meta-analysis. Chest. 2017;152(6):1140-1150. doi:10.1016/j. chest.2017.08.028

23. Crimi C, Heffler E, Augelletti T, et al. Utility of ultrasound assessment of diaphragmatic function before and after pulmonary rehabilitation in COPD patients. Int $J$ Chron Obstruct Pulmon Dis. 2018;13:3131-3139. doi:10.2147/COPD.S171134

24. Marchioni A, Castaniere I, Tonelli R, et al. Ultrasound-assessed diaphragmatic impairment is a predictor of outcomes in patients with acute exacerbation of chronic obstructive pulmonary disease undergoing noninvasive ventilation. Crit Care. 2018;22(1):109. doi:10.1186/s13054-018-2033-x 
25. Nickol AH, Hart N, Hopkinson NS, Moxham J, Simonds A, Polkey MI. Mechanisms of improvement of respiratory failure in patients with restrictive thoracic disease treated with non-invasive ventilation. Thorax. 2005;60(9):754-760. doi:10.1136/ thx.2004.039388

26. Nickol AH, Hart N, Hopkinson NS, et al. Mechanisms of improvement of respiratory failure in patients with COPD treated with NIV. Int J Chron Obstruct Pulmon Dis. 2008;3(3):453-462. doi:10.2147/ COPD.S2705

27. Cammarota G, Sguazzotti I, Zanoni M, et al. Diaphragmatic ultrasound assessment in subjects with acute hypercapnic respiratory failure admitted to the emergency department. Respir Care. 2019;64 (12):1469-1477. doi:10.4187/respcare.06803
28. Lukacsovits J, Carlucci A, Hill N, et al. Physiological changes during low- and high-intensity noninvasive ventilation. Eur Respir J. 2012;39(4):869-875. doi:10.1183/09031936.00056111

29. Dreher M, Schulte L, Muller T, Ekkernkamp E, Zirlik A. Influence of effective noninvasive positive pressure ventilation on inflammatory and cardiovascular biomarkers in stable hypercapnic COPD patients. Respir Med. 2015;109(10):1300-1304. doi:10.1016/j. rmed.2015.08.004

30. Duiverman ML, Maagh P, Magnet FS, et al. Impact of High-Intensity-NIV on the heart in stable COPD: a randomised cross-over pilot study. Respir Res. 2017;18(1):76. doi:10.1186/ s12931-017-0542-9

\section{Publish your work in this journal}

The International Journal of COPD is an international, peer-reviewed journal of therapeutics and pharmacology focusing on concise rapid reporting of clinical studies and reviews in COPD. Special focus is given to the pathophysiological processes underlying the disease, intervention programs, patient focused education, and self management protocols. This journal is indexed on PubMed Central, MedLine and CAS. The manuscript management system is completely online and includes a very quick and fair peer-review system, which is all easy to use. Visit http://www.dovepress.com/testimonials.php to read real quotes from published authors. 